\title{
Safety of thrombolytic treatment in patients with central venous cannulation
}

\author{
Hai Shiang Lee, Tom Quinn, Roger M Boyle
}

Department of Cardiology, York District Hospital.

York

H S Lee

T Quinn

Correspondence to:

Dr H S Lee, Department of Cardiology, Leeds General Infirmary, Great George

Road, Leeds LS1 3EX.

Accepted for publication

19 December 1994

\begin{abstract}
Objectives-To determine the safety of thrombolytic treatment in patients with central venous cannulation.
\end{abstract}

Background-Thrombolytic treatment significantly reduces mortality in patients with myocardial infarction. Because of the fibrinolytic state induced and the potential for haemorrhagic complications, thrombolysis is currently considered a strong relative contraindication in patients who have had central venous cannulation. There are few data available to support this practice.

Methods-Complications in 56 consecutive patients admitted between 1989 and 1992 with infarction and who had cannulation shortly before, or within $24 \mathrm{~h}$ of thrombolysis were studied.

Results-Central venous access was achieved via the subclavian route in $\mathbf{5 2}$ patients, the internal jugular in three, and the supraclavicular in one. The main indications were for inotropic drugs in $\mathbf{1 5}$ patients, pacing in 17, amiodarone infusion in 19, and pressure monitoring in five. Minor haemorrhagic complications occurred in five patients. Two of these patients required either blood or plasma transfusion. Possible major haemorrhagic complications occurred in one patient who became hypotensive shortly after cannulation. Two further patients with severe cardiac failure became hypotensive after cannulation but there was no radiological evidence of effusion and the hypotension was attributed to worsening cardiac failure. Importantly, none of the 19 patients who had cannulas for amiodarone infusion developed significant bleeding complications.

Conclusion-Central cannulation in the fibrinolytic state is associated with a low incidence of important bleeding complications. Thrombolysis should not be withheld in these patients. Cannulation via the subclavian route, however, should be avoided in patients undergoing thrombolysis.

(Br Heart f 1995;73:359-362)

Keywords: myocardial infarction; thrombolytic treatment; central venous cannulation

Acute myocardial infarction is associated with a significant mortality. Major trials in recent years have shown a reduction in infarct size ${ }^{1}$ and mortality when these patients are treated with a thrombolytic agent. ${ }^{2-5}$ Thrombolysis, however, induces a generalised fibrinolytic state which can lead to haemorrhagic complications. For this reason, thrombolytic treatment is considered to be a strong relative or even an absolute contraindication in patients who have had central venous cannulation. ${ }^{67}$ At present, few data are available to support the practice of withholding thrombolytic treatment and to document haemorrhagic complications associated with central venous cannulation.

Central venous cannulation is frequently employed in the management of patients with acute myocardial infarction. Moreover, a significant number of myocardial reinfarctions requiring a repeated dose of thrombolytic agent occur in the first few days after the initial infarction. ${ }^{8}$ Some of these patients would have had recent central venous cannulation and be denied thrombolysis because of a perceived risk of severe bleeding. We studied a consecutive series of patients who had central venous cannulation shortly before or after thrombolytic treatment to determine the safety of thrombolysis in association with central venous cannulation.

\section{Patients and methods}

PATIENTS

All patients admitted to the coronary care unit at York District Hospital between 1989 and 1992 who underwent central line insertion shortly before or within $24 \mathrm{~h}$ of thrombolytic treatment were included in the study. The study comprised 56 patients of whom 35 were male and 21 female patients. Their mean (SD) age was 67 (9) years. The mean (SD) (range) age of the men was 66 (9) (44-82) years and of the women $68(8)(50-81)$ years.

The patients were divided into four groups corresponding to the main indication for central venous cannulation: inotropic drugs, amiodarone, temporary transvenous cardiac pacing, and pressure monitoring. All venous cannulations were performed by either a senior house officer or registrar, qualified for between two and five years. Table 1 summarises the number of patients in each group and their characteristics.

\section{METHODS}

Case notes of all patients included in the study were reviewed by two observers for possible çomplications secondary to central 
Table 1 Patients characteristics

\begin{tabular}{|c|c|c|c|c|}
\hline & Amiodarone & Pacing & Inotropes * & $\begin{array}{l}\text { Pressure } \\
\text { monitoring }\end{array}$ \\
\hline No of patients & 19 & 17 & 15 & 5 \\
\hline $\begin{array}{l}\operatorname{Sex}(M / F) \\
\text { Mean }(S D)\end{array}$ & $16 / 3$ & $8 / 9$ & $9 / 6$ & $2 / 3$ \\
\hline age (years) & $66(9)$ & $68(10)$ & $66(9)$ & $65(7)$ \\
\hline \multicolumn{5}{|c|}{ Myocardial infarction } \\
\hline Anterior & 9 & 2 & 4 & 1 \\
\hline Inferior & 9 & 14 & 9 & 4 \\
\hline Others & $1 \dagger$ & $1 \neq$ & $2 \$ \pi$ & 0 \\
\hline \\
\hline $\begin{array}{l}\text { myocardial } \\
\text { infarction }\end{array}$ & 7 & 2 & 8 & 2 \\
\hline
\end{tabular}

Values are number of patients unless otherwise stated. ${ }^{\star}$ Dobutamine and dopamine, †Left bundle branch block. ¥ Anterior and inferior myocardial infarction. §Electrocardiogram showing ST segment depression without elevation, TPatient paced, unpaced electrocardiogram not available.

venous cannulation. In particular we looked for documented external bleeding or haematoma, haemothorax (on post-procedure chest $x$ ray), low or decreasing central venous pressure, decreasing serum haemoglobin, unexplained hypotension, and death.

Minor haemorrhagic complications are defined as non-life threatening complications resulting from blood loss associated with venous cannulation. These were easily managed conservatively or with blood transfusion. The haemodynamics of the patients were not compromised. Major haemorrhagic complications are defined as significant blood loss resulting in severe hypotension (systolic blood pressure $\leqslant 90 \mathrm{~mm} \mathrm{Hg}$ ) and tachycardia with decreasing central venous pressure. These would be regarded as potentially life threatening.

Table 2 Patients with heart failure and the thrombolytic, anticoagulation, and antiplatelet regimens used in each group of patients

\begin{tabular}{lllll}
\hline & Amiodarone & Pacing & Inotropes & $\begin{array}{l}\text { Pressure } \\
\text { monitoring }\end{array}$ \\
\hline $\begin{array}{l}\text { Congestive cardiac failure before } \\
\text { central venous cannulation }\end{array}$ & 8 & 2 & 15 & 5 \\
$\begin{array}{l}\text { Severe hypotension (Systolic blood } \\
\text { pressure } \leqslant 90 \text { mm Hg) }\end{array}$ & 3 & 1 & 13 & 5 \\
$\begin{array}{l}\text { Thrombolytic agent } \\
\quad \text { Streptokinase }\end{array}$ & 18 & 15 & 14 & 4 \\
$\quad \begin{array}{l}\text { Tissue plasminogen activator } \\
\text { Heparin (full dose) }\end{array}$ & 1 & 2 & 1 & 1 \\
Warfarin & 2 & 2 & 2 & 1 \\
Aspirin & 0 & 0 & 0 & 0 \\
\hline
\end{tabular}

Values are number of patients. ${ }^{\star}$ Dobutamine and dopamine.

Table 3 Characteristics of central venous cannulation

\begin{tabular}{|c|c|c|c|c|c|}
\hline & Amiodarone & Pacing & Inotropes & $\begin{array}{l}\text { Pressure } \\
\text { monitoring }\end{array}$ & $\begin{array}{l}\text { Difficulty associated } \\
\text { with central } \\
\text { venous cannulation }\end{array}$ \\
\hline \multicolumn{6}{|c|}{ Central venous cannulation route: } \\
\hline Subclavian & 17 & 16 & 14 & 5 & $8+$ \\
\hline Internal jugular & 2 & 1 & 0 & 0 & 1 \\
\hline Supraclavicular & 0 & 0 & 1 & 0 & 0 \\
\hline \multicolumn{6}{|l|}{ Device: } \\
\hline Desivalve & 5 & 17 & 4 & 4 & 4 \\
\hline Triple & 12 & 0 & 11 & 1 & 5 \\
\hline Other & $2 \ddagger$ & 0 & 0 & 0 & 0 \\
\hline $\begin{array}{l}\text { Central venous } \\
\text { cannulation }{ }^{\star} \text { difficult }\end{array}$ & 3 & 3 & & 0 & \\
\hline
\end{tabular}

${ }^{\star}$ Documented in the case notes. $\dagger=$ Unable to cannulate the right subclavian vein in two patients (left subclavian vein cannulated instead). Right subclavian arterial puncture in one patient (antecubital vein cannulated instead). $\neq$ One patient had a Wallace device and the other a Leadercath device.
The $\chi^{2}$ test with Yates' correction was used to calculate the difference between two groups of patients.

\section{Results}

PATIENTS

Blood pressure was monitored at $15 \mathrm{~min}$ intervals after central venous cannulation where possible. These data were considered adequate in all patients. Congestive cardiac failure was present in 30 patients before central venous cannulation (table 2). The incidence of congestive cardiac failure and severe hypotension (systolic blood pressure $\leqslant 90$ $\mathrm{mm} \mathrm{Hg}$ ) was higher in patients cannulated for inotropic treatment and pressure monitoring than in those cannulated for amiodarone infusion or cardiac pacing.

\section{THROMBOLYTIC, ANTICOAGULATION AND} ANTIPLATELET TREATMENT

Fifty one $(91 \%)$ of the 56 patients received streptokinase for the treatment of acute myocardial infarction with five patients receiving tissue plasminogen activator (table 2). There were no significant differences between the number of patients receiving streptokinase in each of the patient groups $(P>0.05$ in each case). Seven patients received full dose heparin. Five as routine adjunct with tissue plasminogen activator and two with streptokinase as part of the GUSTO trial. ${ }^{9}$ All other patients received subcutaneous heparin 5000 $\mathrm{U}$ twice daily. No patients were taking concomitant warfarin treatment. Aspirin was given to $44(79 \%)$ of the 56 patients, with no significant difference between each group of patients $(P>0.05$ in each case).

\section{CENTRAL VENOUS CANNULATION}

Table 3 summarises the routes of venous approach and the type of catheter used in each group of patients. Central venous access was obtained via the subclavian route in $\mathbf{5 2}$ patients, the internal jugular in three and the supraclavicular route in one. A single lumen catheter with haemostatic valve (Desivalve, Vygons, Cirencester) was used in 30 patients, a triple lumen catheter in 24, a "Wallace" single lumen catheter over needle device in one, and a "Leadercath" conventional single lumen catheter in one. Central venous cannulation was documented in the case notes of nine patients as being difficult.

One patient was canalised for amiodarone infusion $15 \mathrm{~min}$ after the start of streptokinase. It was discovered $9.5 \mathrm{~h}$ later that the line was arterial. This was confirmed with blood gas measurement. The line was withdrawn and a drum catheter inserted via the antecubital vein. Central venous pressure measurement was stable and chest $x$ ray showed no evidence of haemothorax. Recovery was otherwise uncomplicated.

\section{COMPLICATIONS}

Central venous pressure was serially monitored and the data were judged complete in $20(36 \%)$ of the 56 patients (table 4$)$. Fifteen 
Table 4 Complications and mortality of patients who received central venous cannulation

\begin{tabular}{|c|c|c|c|c|}
\hline & Amiodarone & Pacing & Inotropes* & $\begin{array}{l}\text { Pressure } \\
\text { monitoring }\end{array}$ \\
\hline \multicolumn{5}{|l|}{ Complications: } \\
\hline Major & 0 & 1 & 0 & 0 \\
\hline Minor & 2 & 2 & 1 & 0 \\
\hline \multicolumn{5}{|c|}{ Central venous pressure: } \\
\hline $\begin{array}{l}\text { Measured } \\
\text { Low central }\end{array}$ & 2 & 3 & 10 & 5 \\
\hline $\begin{array}{l}\text { penous } \\
\text { pressure }\end{array}$ & 0 & 0 & 0 & 0 \\
\hline \multicolumn{5}{|l|}{ Chest $x$ ray: } \\
\hline Performed & 13 & 12 & 11 & 1. \\
\hline Effusion & 0 & 1 & 1 & 0 \\
\hline \multicolumn{5}{|l|}{ No of deaths at: } \\
\hline 3 days & 1 & 1 & 9 & 3 \\
\hline 7 days & 4 & 1 & 11 & 3 \\
\hline
\end{tabular}

$(75 \%)$ of these patients were in the inotropic and pressure monitoring groups. No patient had a low or decreasing central venous pressure.

A chest $x$ ray was performed after central venous cannulation in 37 patients. The $x$ ray of two patients showed blunting of the costophrenic angle suggestive of a small pleural effusion. Both chest $x$ rays also showed evidence of pulmonary venous congestion with upper lobe diversion.

\section{HAEMORRHAGIC COMPLICATIONS}

Serial haemoglobin measurement was performed when clinically indicated. Minor bleeding complications occurred in five patients, all of whom had suffered inferior myocardial infarction. Table 5 summarises their characteristics.

Major complications, possibly attributable to central venepuncture, were sustained by a 70 year old woman (patient $A$ ) with an acute anterolateral myocardial infarction treated with streptokinase and aspirin. The patient had a history of myocardial infarction 6 years previously. She developed cardiac failure with increased jugular venous pressure, hypotension (blood pressure $80 / 60 \mathrm{~mm} \mathrm{Hg}$ ), and low urine output. Right subclavian venous access was obtained with difficulty for dobutamine and dopamine infusion $(7 \cdot 45 \mathrm{~h}$ after initiation of streptokinase). At $1 \mathrm{~h}$ postprocedure, her blood pressure suddenly

Table 5 Minor haemorrhagic complications

\begin{tabular}{llllll}
\hline Patient & Sex & $\begin{array}{l}\text { Age } \\
\text { (years) }\end{array}$ & Aspirin & Complications & Management \\
\hline $1^{\star}$ & F & 81 & Yes & $\begin{array}{l}\text { Prolonged bleeding from } \\
\text { puncture site } \\
\text { Haemoglobin dropped from } \\
11 \cdot 2 \text { to } 9 \cdot 3 \text { dg/l in } 4 \text { days }\end{array}$ & $\begin{array}{l}\text { Two units of } \\
\text { fresh frozen plasma } \\
\text { Two units of blood }\end{array}$ \\
3 & F & 55 & Yes & $\begin{array}{l}\text { Moderate haematoma } \\
\text { Moderate bleeding from } \\
\text { puncture site } \\
\text { Bleeding from puncture } \\
\text { site }\end{array}$ & $\begin{array}{l}\text { None } \\
\text { Pressure dressing }\end{array}$ \\
4 & M & 78 & Yes & No & Yessure dressing \\
5 & M & 47 & & &
\end{tabular}

No other cause of anaemia was noted. became unrecordable and her heart rate increased to 130 beats/min. Her dobutamine dose was increased and a peak systolic pressure of $90 \mathrm{~mm} \mathrm{Hg}$ was achieved. She died of continuing cardiac failure, however, $25.5 \mathrm{~h}$ after venous cannulation. No post-procedural chest $x$ ray was performed and central venous pressure was not monitored as her jugular venous pressure was persistently raised.

Two further patients developed hypotension after venous cannulation. A 65 year old man (patient B) with a history of three previous myocardial infarctions suffered a further anteroseptal infarction and was treated with streptokinase. $\mathrm{He}$ was receiving longterm dipyridamole treatment. A subclavian venous line was inserted $(8 \cdot 25 \mathrm{~h}$ after starting streptokinase) for amiodarone, dobutamine, and dopamine infusion after cardiac arrest with ventricular fibrillation and severe pulmonary oedema post-arrest. His blood pressure decreased from a post-arrest measurement of $110 / 60 \mathrm{~mm} \mathrm{Hg}$ to $50 / 35 \mathrm{~mm}$ $\mathrm{Hg}$ after venous cannulation. He died $90 \mathrm{~min}$ after cannulation. A 73 year old man (patient C) treated with streptokinase for inferior infarction developed complete heart block requiring temporary pacing. This was attempted without success from the right subclavian approach ( $3 \mathrm{~h}$ after starting streptokinase) and was inserted through the left subclavian vein. The patient had continuous bleeding and a large bruise on the right puncture site. He became hypotensive (blood pressure decreased from $100 / 60 \mathrm{~mm} \mathrm{Hg}$ to $55 / 40$ $\mathrm{mm} \mathrm{Hg}$ ) with loss of consciousness $4 \mathrm{~h}$ after venous cannulation. $\mathrm{He}$ died $16.5 \mathrm{~h}$ after the procedure. Both patients had a postprocedural chest $x$ ray with no evidence of effusion. Cardiac failure was the likely cause of hypotension.

\section{MORTALITY}

Fourteen patients $(25 \%)$ died within three days of admission. Twelve $(86 \%)$ of these patients were in the inotropic or pressure monitoring groups. Mortality in these two groups was significantly higher than in the amiodarone $\left(\chi^{2}=10.8, P<0.01\right)$ and pacing groups $\left(\chi^{2}=9.55, P<0.01\right)$ in which one patient of each group died. Three further patients in the amiodarone and two in the inotropic group died of worsening cardiac failure by day 7 .

\section{Discussion}

Central venous cannulation to facilitate drug administration, pressure monitoring, or temporary transvenous pacing is not uncommon in the setting of acute myocardial infarction. It does, however, present the clinician with an additional potential hazard to consider when weighing up the relative risks and benefits of thrombolytic treatment in a patient with infarction and a central line already inserted. Some authorities regard even one unsuccessful attempt at central line placement as an important contraindication to thrombolysis. ${ }^{67}$ There are, however, few data available to 
support this practice. The results of this study suggest that central venous cannulation is associated with a low incidence of significant bleeding complications in the presence of thrombolysis.

We included only patients who received central venous cannulation within $24 \mathrm{~h}$ of thrombolytic treatment because fibrinogen levels are known to be reduced and patients are at increased risk of haemorrhage during that time interval. ${ }^{1011}$

Major haemorrhagic complications directly attributable to central venepuncture possibly occurred in one patient. Even then patient A was already in significant cardiac failure before venous cannulation and cardiogenic shock was equally likely to have been the cause of hypotension. Unfortunately, this patient did not have a post-cannulation chest $x$ ray and a haemothorax could not be confidently excluded. Patients $B$ and $C$ were in significant cardiac failure before central venous cannulation. The cause of hypotension was likely to be cardiac failure as significant bleeding would have been demonstrated in the post-cannulation chest $x$ ray.

Most patients with congestive cardiac failure and significant hypotension were in the inotropic group. The mortality in these patients would be expected to be high. This is the case in our patients with a three day mortality of $60 \%$. We chose to examine three day mortality because haemorrhagic complications are unlikely to be the main cause of death after this time. The seven day mortality is also listed in table 4 for comparison. Importantly, only one (5\%) of the 19 patients in the amiodarone group and one $(6 \%)$ in the pacing group died within three days. The patient receiving amiodarone who died was canalised via the internal jugular venous route during cardiac arrest. The patient was in ventricular fibrillation and despite amiodarone resuscitation failed. The patient in the pacing group who died has already been described (patient C).

Only one patient in this series sustained potentially life threatening complications. Thrombolytic treatment, as well as reducing morbidity, ${ }^{1}$ is known to reduce mortality in patients with acute myocardial infarction by approximately $25 \% .^{2-5}$ The benefit might be even greater in patients with concomitant severe cardiac failure. ${ }^{12}$ These benefits would seem to outweigh the potential complications of inducing a fibrinolytic state in a patient with central venous cannulation. A significant number of myocardial reinfarctions requiring a repeated dose of thrombolytic agent occurred in the first few days after the initial infarction. ${ }^{8}$ Some of these patients would have had recent central venous cannulation. It seems important not to deny these patients further thrombolysis as their mortality would be particularly high.

This study, however, does demonstrate possible serious complications associated with central venous cannulation and thrombolytic treatment. Two patients with minor haemorrhagic complications required blood or fresh frozen plasma transfusion, and blood loss may have been a factor responsible for hypotension in patient A. Physicians are traditionally trained to achieve central venous assess via the subclavian vein. In view of the potential hazard associated with this practice, especially in the era of thrombolysis, it would seem prudent for physicians to be acquainted with central cannulation via a more compressible and visible route such as the femoral, brachial, or jugular vein.

Our results suggest that thrombolytic treatment in patients with central venous cannulation is associated with a low incidence of important bleeding complications. We conclude that similar to cardiopulmonary resuscitation, ${ }^{1314}$ central venous cannulation is not a clear contraindication to thrombolytic treatment. It would seem prudent, however, to use the femoral, jugular, or brachial veins ${ }^{1516}$ for cannulation of patients undergoing thrombolysis provided that appropriate training in the use of these routes is undertaken.

1 ISAM Study Group. A prospective trial of intravenous streptokinase in acute myocardial infarction (ISAM): mortality, morbidity, and infarct size at 21 days. $N$ Engl $\mathcal{F}$ Med 1986;314:1465-71.

2 ISIS-2 (Second International Study of Infarct Survival) Collaborative Group. Randomised trial of intravenous streptokinase, oral aspirin, both or neither among 17,187 cases of suspected acute myocardial infarction: ISIS-2. Lancet 1988;ii:349-60.

3 GISSI (Gruppo Italiano per lo Studio della Streptochinasi nell'Infarto Miocardico). Effectiveness of intravenous thrombolytic treatment in acute myocardial infarction. Lancet 1986;i:397-402.

4 AIMS (Anistreplase Intervention Mortality Study) Trial Study Group. Effects of intravenous APSAC on mortality after acute myocardial infarction: preliminary report of a placebo controlled trial. Lancet 1988;i:545-9.

5 Wilcox RG, Von der Lippe G, Olsson CG, et al. Effects of alteplase in acute myocardial infarction: 6-month results from the ASSET study. Anglo-Scandinavian study of early thrombolysis. Lancet 1990;335:1175-8.

6 American Heart Association. Guidelines for cardiopulmonary resuscitation and emergency cardiac care. monary resuscitation and en

7 European Resuscitation Council. Adult advanced cardiac life support: the European Resuscitation Council guidelife support: the European Resuscitation Council
lines 1992 (abridged). BMf 1993;306:1589-93.

8 Rivers JT, White HD, Cross DB, Williams BF, Norris RM. Re-infarction after thrombolytic therapy for acute myocardial infarction followed by conservative management: incidence and effect of smoking. $\mathcal{F} \mathrm{Am}$ Coll Cardiol 1990;16:340-8.

9 The GUSTO investigators. An international randomized trial comparing four thrombolytic strategies for acute myocardial infarction. $N$ Engl f Med 1993;329:673-82.

10 Hoffman JJML, Bonnier JJRM, De Swart JBRM. Systemic effect of thrombolytic drugs in acute myocardial infarction: comparison of intravenous APSAC (BRL 26921) and intracoronary streptokinase. Fibrinolysis 1987;1: 225-30.

11 Marder VJ. Comparison of thrombolytic agents: selected haematologic, vascular and clinical events. Am $\mathcal{f}$ Cardiol 1989;64:2-7A.

12 Umachandran V, Ranjadayalan K, Kopelman PG, Timmis AD. Thrombolytic therapy in high risk subgroups: morAD. Thrombolytic therapy in high risk subgroups: morbidity and mortality benefits
Eur Heart $₹$ 1991;12:321.

13 Cross SJ, Lee HS, Rawles JM, Jennings K. Safety of thrombolysis in association with cardiopulmonary resuscitation. BMF 1991;303:1242.

14 Van Campen CMC, Van Leeuwen GR, Verheugt FWA. Safety and efficacy of thrombolysis for acute myocardial infarction in patients with prolonged cardiopulmonary resuscitation. Eur Heart f 1993;14:738.

15 Medical Practice Committee and Council of the British Cardiac Society: choice of route for insertion of temporary pacing wires. Br Heart $\mathcal{F} 1993 ; 70: 592$.

16 Murphy J, Stephenson C. Survey of venous access for temporary pacing in the UK. Br Heart $\mathcal{F} 1994 ; 71$ (May suppl):P41. 